\title{
Manipulation of Lipid Rafts in Neuronal Cells
}

\author{
Gunter P. Eckert*
}

Goethe-University, Dept. Pharmacology, Biocenter N260 R1.09, Max-von-Laue Str. 9, D-60438 Frankfurt, Germany

\begin{abstract}
Lipid rafts are specialized plasma membrane micro-domains highly enriched in cholesterol, sphingolipids and glycosylphosphatidylinositol (GPI) anchored proteins. Lipid rafts are thought to be located in the exofacial leaflet of plasma membranes. Functionally, lipid rafts are involved in intracellular trafficking of proteins and lipids, secretory and endocytotic pathways, signal transduction, inflammation and in cell-surface proteolysis. There has been substantial interest in lipid rafts in brain, both with respect to normal functioning and with certain neurodegenerative diseases. Based on the impact of lipid rafts on multitude biochemical pathways, modulation of lipid rafts is used to study related disease pathways and probably offers a target for pharmacological intervention. Lipid rafts can be targeted by modulation of its main components, namely cholesterol and sphingolipids. Other approaches include the modulation of membrane dynamics and it has been reported that protein-lipid interactions can vary the occurrence and composition of these membrane micro-domains. The present review summarizes the possibilities to modulate lipid rafts with focus on neuronal cells.
\end{abstract}

Keywords: Lipid raft, cholesterol, membrane fluidity, statin, cyclodextrine, docosahexaenoic acid.

\section{IMPACT OF LIPID RAFTS FOR PHYSIOLOGICAL AND PATHOPHYSIOLOGICAL FUNCTIONS IN THE CNS}

Lipid rafts are specialized plasma membrane microdomains highly enriched in cholesterol, sphingolipids, sphingomyelin [SM], gangliosides (GM)) and glycosylphosphatidylinositol (GPI) anchored proteins [1]. Alternatively, lipid rafts have been named as detergent insoluble glycolipid enriched membranes or detergent - resistant membranes [2]. Caveolae are defined as membrane invaginations enriched in cholesterol and glycosphingolipids containing the protein caveolin, which play a role in endocytosis [3]. The reader is referred to recently published reviews for a comprehensive and detailed discussion of lipid rafts [1, 4-6]. The present review summarizes the impact and possibilities to modulate lipid rafts with focus on neuronal cells.

Lipid rafts are thought to be located in the exofacial leaflet of plasma membranes [7], although it has been suggested that lipid rafts may also be found in the cytofacial leaflet [8]. Potential explanations for raft formation include the preference of cholesterol for the saturated acyl chains of sphingolipids compared with glycerophospholipids and the dynamic interactions of protein-lipid and protein-protein linkages $[6,9]$. An additional mechanism has been proposed whereby proteins are encased in a "lipid-shell" of cholesterol and sphingolipids $[10,11]$.

The majority of studies on lipid rafts have used methods that takes advantage of the insolubility of the lipid fraction of membranes in detergents such as Triton X-100 [12-15]. There is evidence indicating that the composition of the

*Address correspondence to this author at the Goethe-University, Dept. Pharmacology, Biocenter N260 R1.09, Max-von-Laue Str. 9, D-60438 Frankfurt, Germany; Tel: +49 69798 29378; E-mail: G.P.Eckert@em.unifrankfurt.de; Web: www.eckert-science.de isolated lipid rafts may differ depending on whether a detergent is used [16-18]. It has been argued that the use of detergents may actually induce formation of detergent - resistant lipid domains and not to be representative for physiological membrane structures [19]. In addition, it has also been observed that different detergent/lipid ratios and starting materials can influence the lipid and protein composition, making comparisons among studies difficult [4]. Since it was suspected that the presence of detergent could produce artifacts, the use of non-detergent methods has been suggested $[8,20]$. Accordingly, studies on brain synaptosomes revealed differences both qualitatively and quantitatively in proteins and lipids when detergent and nondetergent methods were applied [20, 21]. Beside the biochemical characterization of isolated membrane fractions, different techniques for studying lipid rafts in situ such as functional imaging, cytometry, two-photon microscopy, electron microscopy, fluorescent-quenching and resonance energy transfer techniques have been developed [22-29].

Functionally, lipid rafts are involved in intracellular trafficking of proteins and lipids, secretory and endocytic pathways, inflammation and in cell-surface proteolysis [16, 30-34]. In the brain, there has been substantial interest in lipid rafts, with respect to both normal functioning and certain neurodegenerative diseases. It is well accepted that lipid rafts play an important role for signaling processes in the central nervous system [7]. Synaptic proteins such as synaptophysin or synaptotagmin associate with lipid rafts [35-38] and lipid rafts play a role in the control of post synaptic membrane viscosity [39]. Moreover, brain-derived neurotrophic factor, which exerts multiple biological functions in the CNS increased the levels of presynaptic proteins in lipid rafts of neurons [40]. Regulation of the glutamateric neurotransmission, which is involved in the formation of spatial memory, represents one example for the impact of lipid rafts on classical signaling processes [41]. 
Accordingly, NMDA-, AMPA- and metabotrobic glutamate receptors are regulated by lipid raft related pathways [42-44]. However, excess of extracellular glutamate induced by cerebral ischemia leads to neuronal cell death, which is accompanied by increased phosphorylation and redistribution of NMDA receptors between synaptic lipid rafts and post-synaptic densities in the rat brain [45].

Lipid rafts have been attracted attention in neurodegeneration, such as Prion diseases, Parkinson's disease and especially in AD [46-48]. Recently, alterations in lipid rafts isolated from AD brain were reported [49], including the localization of active $\gamma$-secretase in lipid rafts in human brain [50]. Active $\gamma$-secretase is involved in the pathological proce-ssing of the $\mathrm{AD}$ related amyloid precursor protein (APP). Neurotoxic $\beta$-amyloid peptide (A $\beta$ ) is a product of the secretase cleavage of APP and both proteins have been located in lipid rafts [26, 51-54]. Moreover, it was demonstrated that the presenilin-1 protein, which is part of the $\gamma$-secretase complex, induces lipid raft formation in vivo [55].

Gradual changes in steady-state levels of $A \beta$ in brain are considered as an initial step in the amyloid cascade hypothesis of $\mathrm{AD}$. There is evidence that the membrane lipid environment may modulate secretase activity and alters its function. Cleavage of APP strongly depends on membrane properties and it was shown that $\mathrm{A} \beta$-oligomers from $\mathrm{AD}$ brains associate with a detergent-resistant membrane fraction in a cholesterol-dependent manner [56]. Since A $\beta$ perturbs cell membrane fluidity, the cell membrane may be the location where the neurotoxic cascade of A is initiated. Based on the observation that $A \beta$ binds to lipid raft related ganglioside GM-1 [57] the effects of oligomeric $A \beta$ on membrane fluidity of whole living cells, the impact of exogenous and cellular A $\beta$ on the processing of APP and the role of GM-1 ganglioside was tested recently [58]. Evidence was presented that oligomeric $A \beta$ stimulates the amyloidogenic processing of APP by reducing membrane fluidity and complexing with GM-1 ganglioside. It was concluded that this dynamic action of $A \beta$ might start a vicious circle, where endogenous $A \beta$ stimulates its own production [58].

In brains of $\mathrm{AD}$ patients, abundance of raft related flotillin proteins was reported to increase with progression of A deposition [59, 60]. However, abundance of flotillin-1 was reduced in lipid rafts isolated from mice harboring human apoE4, which represent an AD model [61]. Although, the function of flotillin is not well understood, it was proposed that it plays a role for neuronal regeneration [62, 63]. Sphingomyelin represent one of the major glycosphingolipids present in lipid rafts [17]. Changing sphingomyelin levels modify lipid raft structure and function $[5,64,65]$. Sphingomyelin levels were significantly lower in the lipid rafts isolated from synaptosomes of 12- and 24- month-old apoE4 mice in contrast to the 2-month-old apoE4 mice [61].

Based on the impact of lipid rafts on multitude biochemical pathways, modulation of lipid rafts is used to study related disease pathway and probably offers a target for pharmacological intervention. Lipid rafts can be targeted by modulation of its main components, namely cholesterol, sphingo- and ganglioside lipids. Other approaches include the modulation of membrane biophysical parameters such as fatty acid composition.

\section{MEMBRANE CHOLESTEROL AND SPHINGO- MYELIN - TARGETS FOR THE MODULATION OF LIPID RAFTS}

Cholesterol is known to be essential for the functional activity of physiological membranes [66, 67] and plays an essential role in the regulation of synaptic function and plasticity $[68,69]$. The highest cellular cholesterol load is found within the plasma membrane (PM). Levels and distribution of PM cholesterol are tightly regulated by the cell [70]. The capacity of the PM to incorporate cholesterol is largely a function of its sphingomyelin content [67]. PM polarity is conditioned by the asymmetric insertion of cholesterol as well as functional proteins and phospholipids. Inside the PM, about $70-85 \%$ of free cholesterol resides in the cytofacial bilayer leaflet, whereas only about $15-30 \%$ join the exofacial leaflet $[67,71,72]$. Even in this outer membrane domain the intra-membrane distribution of cholesterol follows a strict organization into structural pools and is altered during aging [73]. Cholesterol builds up lateral membrane domains or kinetic pools that probably mediate cellular cholesterol efflux and participate in the formation lipid raft domains [67].

Cholesterol is highly enriched in lipid rafts [17] and evidence suggest that cholesterol condenses the packing of the sphingolipid molecules and thus cholesterol-sphingolipid microdomains form a separate lipid ordered phase in the exofacial leaflet of the membrane [74, 75]. Cholesterol levels and consequently lipid raft structure can be modulated either by physical extraction from the plasma membrane in vitro or by inhibition of the cellular biosynthesis using specific enzyme inhibitors in vivo. Changing membrane cholesterol domains also affect the cellular cholesterol homeostasis. Non-raft cholesterol pool within the plasma membrane primarily senses the amount of cellular bulk cholesterol [76]. Changing sphingomyelin levels modify lipid raft structure and function [5, 64, 65]. Raft destruction with sphingomyelinase shuttles cholesterol into the non-raft pool, which probably flows back to the endoplasmatic reticulum and thus blocks the intracellular translocation of the SREBP-SCAP complex to the Golgi and further cholesterol synthesis [76, 77].

\section{METHYL- $\beta$-CYCLODEXTRIN - A BIOPHYSICAL TOOL TO MODULATE MEMBRANE CHOLES- TEROL LEVELS}

Cyclodextrins are torus-shaped cyclic oligosaccharides containing at least six glucose units attached by glycosidic bonds. They possess a hydrophilic outer surface and a hydrophobic inner cavity. Cyclodextrins enhance the solubility of non-polar substances (e.g., cholesterol) by incorporating them into their hydrophobic cavity and forming non-covalent water-soluble inclusion complexes. Cyclodextrins comprised of 6,7 , and 8 glucose units $(\alpha-, \beta$ and $\gamma$-forms, respectively) were used to alter the lipid composition of cells. Among those, $\beta$-cyclodextrins and derivatives thereof such as methyl- $\beta$-cyclodextrin $(\mathrm{M} \beta \mathrm{CD})$ or 2-hydroxypropyl- $\beta$-cyclodextrin were found to selectively extract cholesterol from the plasma membrane, in preference to other membrane lipids [78]. M $\beta C D$ affects membrane raft domains and modulates the location of raft-related proteins 
$[23,79,80]$. Hence, $\mathrm{M} \beta \mathrm{CD}$ is commonly used to study lipid raft related processes in neuronal cells such as receptor mediated signaling [81-83] or processes related to neurodegeneration $[66,84-88]$. Recently, the mechanism how M $\beta C D$ affect lipid rafts was studied in more detail: Treatment of synaptosomal plasma membranes (SPM) isolated from mouse brains with $\mathrm{M} \beta \mathrm{CD}$ significantly lowered SPM free cholesterol levels and the opposite was observed when cholesterol inclusion complexes were used [89]. Interestingly, $M \beta C D$ treatment resulted in significantly reduced exofacial percent cholesterol values in the membrane bilayer of SPM, leading to decreased exofacial to cytofacial cholesterol ratio values [89]. The idea that M $\beta C D$ preferentially extracts cholesterol from the detergent insoluble areas of the plasma membrane, is supported by the stronger reduction in cholesterol content of the lipid raft fractions from human T-cell lymphoblastic leukaemia cells after $\mathrm{M} \beta \mathrm{CD}$ incubation ( $\sim 88 \%$ reduction) compared to the membrane preparations $(\sim 50 \%$ reduction) and crude cell lysate $(\sim 30 \%)$ preparation [90]. Hence, it could be concluded that $\mathrm{M} \beta C D$ exclusively extracts exofacial membrane cholesterol pools. Reversely, cholesterol enrichment with M $B C D-$ cholesterol complexes induces contagious effects in SPM: Percent exofacial cholesterol levels are clearly enhanced. Accordingly, exofacial to cytofacial cholesterol ratio values were significantly increased in SPM of mice [89]. These data indicate that exofacial membrane cholesterol pools are most sensitive to external cholesterol manipulations using $\mathrm{M} \beta C D$ complexes, where lipid raft domains reside [91].

\section{STATINS - INHIBITORS OF THE CHOLESTEROL BIOSYNTHESIS}

Statins are inhibitors of 3-hydroxy-3-methylglutaryl coenzyme A (HMG-CoA) reductase the rate-limiting enzyme in cholesterol biosynthesis [92]. The inhibition of HMG-CoA reductase not only prevents cholesterol biosynthesis and induce significant plasma cholesterol reductions [93], but also affects the isoprenoid pathway, which accounts for statin's pleiotropic effects $[94,95]$. Simvastatin and lovastatin are prodrug lactone forms that are transformed to the active acid forms mainly by hepatocytes. Lipophilicity is further characterized by the behavior of compounds on the octanol/water phase. Based on the logarithm of the partition coefficient simvastatin, lovastatin, cerivastatin, fluvastatin, pitavastatin and atorvastatin are lipophilic, while pravastatin is hydrophilic [96]. Rosuvastatin is a relatively new statin, having a polar methane sulphonamide group, and it can be placed between cerivastatin and pravastatin [96]. Lactone and active acid forms of simvastatin and lovastatin were determined in picomolar levels in mouse brains after oral administration [97].

Recently, the effects of statins including lovastatin and simvastatin as lipophilic agents as well as pravastatin as a hydrophilic compound was studied focussing on their efficiency to affect subcellular membrane cholesterol pools in synaptosomal plasma membranes (SPM) of mice [72]. In contrast to the hydrophilic pravastatin, the lipophilic lovastatin and simvastatin strongly reduced the levels of free cholesterol in SPM, confirming earlier data [98]. Interestingly, statins significantly reduced cholesterol levels in the exofacial membrane leaflet. These changes were accom- panied by modified membrane bulk fluidity. All three statins reduced the expression of the raft marker protein flotillin-1, which indicates that statins modulate lipid rafts in vivo [72]. Accordingly, Burns et al. demonstrated that changes in the distribution of cholesterol between the cyto- and exofacial membrane leaflet were directly related to lower levels of $A \beta$, a lipid raft related process with impact on AD pathology (see above) [99].

Neuroprotective effects of statins have been reported, including protection from NMDA-induced neuronal death $[100,101]$. Excess of brain extracellular glutamate after cerebral ischemia over-activates NMDA receptors, which subsequently leads to neuronal death [102]. Since NMDA receptors have been reported to be associated with lipid rafts, the effect of simvastatin on levels on excitotoxicity and on association of NMDA receptors to lipid rafts was investigated recently. The data demonstrated that reduction of membrane cholesterol levels protects from NMDA-induced neuronal damage probably by reducing the association of NMDA receptors from lipid rafts [102].

\section{SEQUESTRATION OF CHOLESTEROL BY FILIPIN}

Filipin represents a polyene antibiotic with macrolide structure and amphipatic nature, which forms a fluorescent complex with cholesterol and is commonly used to visualize the cellular distribution of free cholesterol [78]. Since filipin sequesters cholesterol it is also used to disrupt lipid raft structures [103-105]. For its action filipin requires a sterol partner with a free 3-OH group and it was speculated that filipin may form large planar aggregates between the two layers of the membrane, it may be absorbed at the membrane surface or located at the upper layer of the membrane [106]. However, different models have been generated to explain the organization of filipin-sterol complexes within the membrane bilayer [78]. Filipin is a cytotoxic compound and disrupts the integrity of sterol-containing membranes. Thus, sequestering of cholesterol using filipin should only be employed in fixed cells or tissues [78].

\section{LONG-CHAIN POLYUNSATURATED FATTY ACIDS MODULATE LIPID RAFTS}

Omega-3 fatty acids are taken up by virtually all body cells and affect membrane composition, eicosanoid biosynthesis, cell signaling cascades, and gene expression [107]. Long-chain polyunsaturated fatty acids (LC-PUFA) like eicosapentaenoic acid (EPA, 20:5, n-3) and docosahexaenoic acid (DHA, 22:6, n-3) are especially important during human brain development. Maternal deficiency of omega-3 fatty acids leads to deficits in neurogenesis, neurotransmitter metabolism, and altered learning and visual function in animals [108] and may result in several neurological disorders [107]. Among various organs, in the brain omega-3 fatty acids are most extensively studied. In fact, the brain is the organ richest in lipids and it was shown that the differentiation and functioning of cultured brain cells requires LC-PUFA [109].

A number of studies have demonstrated that dietary LCPUFA are incorporated into diverse cell types and appear to uniquely modulate cell membrane micro-domains [110-113]. 
Using a T-cell model, Stulnig et al. showed the ability of PUFA enrichment to selectively modify the cytoplasmic layer of lipid rafts $[113,114]$. Accordingly, Chapkin and coworkers showed that dietary n-3 PUFA reduced lipid raft sphingolipid content and altered raft fatty acid composition $[110,115,116]$. Recently, the same group studied the effects of DHA on the size and distribution of lipid rafts in living HeLa cells [117]. Selected PUFA can increase the clustering of proteins in cholesterol-dependent micro-domains, whereas non-raft mirco-domains were insensitive to DHA modulation [117]. The impact of these findings for neurodegenerative diseases is underlined by reports that DHA enhanced synaptic membrane fluidity in aged mice [118] and decreased $\mathrm{A} \beta$ levels in cells and in brains of murine AD models [119123]. Moreover, lipid rafts from AD brains displayed abnormally low levels of LC-PUFA, as well as reduced unsaturation and peroxidation indexes [49].

LC-PUFA alter the basic properties of cell membranes and enhances membrane viscosity [124]. It was suggested that because of its polyunsaturation, PUFA are sterically incompatible with sphingolipid and cholesterol and, therefore appear to alter lipid raft behavior and protein function [125-127].

\section{CONCLUSIONS}

In summary, lipid raft signaling is involved in multitude biochemical pathways. Modulation of cholesterol using physical extraction by methyl- $\beta$-cyclodextrine, filipin or inhibition of cholesterol biosynthesis by statins is most commonly used to change lipid rafts in membranes. Size and distribution of lipid rafts depend also on the membrane environment, which could be chanced by long-chain polyunsaturated fatty acids. The alteration of lipid rafts represents a useful tool to study related disease pathways and probably offers a target for pharmacological intervention. However, it is not defined yet if targeting lipid rafts in vivo might impair physiological functions. For instance, it is not clear whether dietary LC-PUFA are incorporated into raft lipids or whether their low affinity to cholesterol disallows this and causes phase separation from rafts and displacement of raft proteins [128]. Moreover, it was shown that depletion of cholesterol leads to instability of surface AMPA-glutamate in lipid rafts, which was accompanied by gradual loss of synapses and dendritic spines [129].

\section{REFERENCES}

[1] Fielding CJ, Fielding PE. Relationship between cholesterol trafficking and signaling in rafts and caveolae. Biochim Biophys Acta 2003; 1610: 219-28.

[2] Quest AF, Leyton L, Parraga M. Caveolins, caveolae, and lipid rafts in cellular transport, signaling, and disease. Biochem Cell Biol 2004; 82: 129-44.

[3] Yamada E. The fine structure of the gall bladder epithelium of the mouse. J Biophys Biochem Cytol 1955; 1: 445-58.

[4] Edidin M. The state of lipid rafts: from model membranes to cells. Annu Rev Biophys Biomol Struct 2003; 32: 257-83.

[5] Sonnino S, Prinetti A, Mauri L, et al. Dynamic and structural properties of sphingolipids as driving forces for the formation of membrane domains. Chem Rev 2006; 106: 2111-25.

[6] Epand RM. Proteins and cholesterol-rich domains. Biochim Biophys Acta 2008; 1778: 1576-82.
[7] Simons K, Toomre D. Lipid Rafts and Signal Transduction. Nat Rev Mol Cell Biol 2000; 1: 31-9.

[8] Brown DA, London E. Structure and function of sphingolipid- and cholesterol-rich membrane rafts. J Biol Chem 2000; 275: 17221-4.

[9] Lai EC. Lipid rafts make for slippery platforms. J Cell Biol 2003; 162: $365-70$

[10] Anderson RG, Jacobson K. A role for lipid shells in targeting proteins to caveolae, rafts, and other lipid domains. Science 2002; 296: $1821-5$

[11] Wood WG, Igbabvoa U, Eckert GP, et al. Cholesterol - A Janus Face molecule in the central nerous system. In: Lajtha A, Reith M, Eds. Neural membranes and transport. New York: Plenum Press 2007; p. 513

[12] Lee SJ, Liyanage U, Bickel PE, et al. A detergent-insoluble membrane compartment contains A in vivo. Nat Med 1998; 4: 7304.

[13] Oshima N, Morishima-Kawashima M, Yamaguchi $\mathrm{H}$, et al. Accumulation of amyloid beta-protein in the low-density membrane domain accurately reflects the extent of beta-amyloid deposition in the brain. Am J Pathol 2001; 158: 2209-18.

[14] Maekawa S, Morii $\mathrm{H}$, Kumanogoh $\mathrm{H}$, et al. Localization of neuronal growth-associated, microtubule-destabilizing factor scg 10 in brain-derived raft membrane microdomains. J Biochem 2001; 129: 691-7.

[15] Martens JR, Navarro-Polanco R, Coppock EA, et al. Differential targeting of Shaker-like potassium channels to lipid rafts. J Biol Chem 2000; 275: 7443-6.

[16] Brown DA, London E. Functions of lipid rafts in biological membranes. Annu Rev Cell Dev Biol 1998; 14: 111-36.

[17] Hooper NM. Detergent-insoluble glycosphingolipid/cholesterolrich membrane domains, lipid rafts and caveolae. Mol Membr Biol 1999; 16: 145-56.

[18] Smart EJ, Ying YS, Mineo C, et al. A detergent-free method for purifying caveolae membrane from tissue culture cells. Proc Natl Acad Sci USA 1995; 92: 10104-8.

[19] Lichtenberg D, Goni FM, Heerklotz H. Detergent-resistant membranes should not be identified with membrane rafts. Trends Biochem Sci 2005; 30: 430-6.

[20] Persaud-Sawin DA, Lightcap S, Harry GJ. Isolation of rafts from mouse brain tissue by a detergent-free method. J Lipid Res 2009 ; 50: 759-67.

[21] Eckert GP, Igbavboa U, Müller WE, et al. Lipid rafts of purified mouse brain synaptosomes prepared with or without detergent reveal different lipid and protein domains. Brain Res 2003; 962: 144-50.

[22] Duggan J, Jamal G, Tilley M, et al. Functional imaging of microdomains in cell membranes. Eur Biophys J 2008; 37: 127989.

[23] Hao M, Mukherjee S, Maxfield FR. Cholesterol depletion induces large scale domain segregation in living cell membranes. Proc Natl Acad Sci USA 2001; 98: 13072-7.

[24] Ishitsuka R, Sato SB, Kobayashi T. Imaging lipid rafts. J Biochem 2005; 137: 249-54.

[25] Kiss E, Nagy P, Balogh A, et al. Cytometry of raft and caveola membrane microdomains: from flow and imaging techniques to high throughput screening assays. Cytometry A 2008; 73: 599-14.

[26] Peters I, Igbabvoa U, Schütt $T$, et al. The interaction of beta amyloid peptide with cellular membranes stimulates its own production. Biochim Biophys Acta 2009; 1788: 964-72.

[27] Raunser S, Haase W, Franke C, et al. Heterologously expressed GLT-1 associates in approximately $200-\mathrm{nm}$ protein-lipid islands. Biophys J 2006; 91: 3718-26.

[28] Silvius JR, Nabi IR. Fluorescence-quenching and resonance energy transfer studies of lipid microdomains in model and biological membranes. Mol Membr Biol 2006; 23: 5-16.

[29] Rao M, Mayor S. Use of Forster's resonance energy transfer microscopy to study lipid rafts. Biochim Biophys Acta 2005; 1746: 221-33.

[30] Chichili GR, Rodgers W. Cytoskeleton-membrane interactions in membrane raft structure. Cell Mol Life Sci 2009; 66: 2319-28. 
[31] Hanzal-Bayer MF, Hancock JF. Lipid rafts and membrane traffic. FEBS Lett 2007; 581: 2098-104.

[32] Ikonen E. Roles of lipid rafts in membrane transport. Curr Opin Cell Biol 2001; 13: 470-7.

[33] Kabouridis PS, Jury EC. Lipid rafts and T-lymphocyte function: implications for autoimmunity. FEBS Lett 2008; 582: 3711-18.

[34] Lajoie P, Nabi IR. Regulation of raft-dependent endocytosis. J Cell Mol Med 2007; 11: 644-53.

[35] Chamberlain LH, Burgoyne RD, Gould GW. SNARE proteins are highly enriched in lipid rafts in PC12 cells: implications for the spatial control of exocytosis. Proc Natl Acad Sci USA 2001; 98: 5619-24.

[36] Gil C, Cubi R, Blasi J, et al. Synaptic proteins associate with a subset of lipid rafts when isolated from nerve endings at physiological temperature. Biochem Biophys Res Commun 2006; 348: 1334-42.

[37] Lang T. SNARE proteins and 'membrane rafts'. J Physiol 2007; 585: 693-8.

[38] Lv JH, He L, Sui SF. Lipid rafts association of synaptotagmin I on synaptic vesicles. Biochemistry 2008; 73: 283-8.

[39] Renner M, Choquet D, Triller A. Control of the postsynaptic membrane viscosity. J Neurosci 2009; 29: 2926-37.

[40] Suzuki S, Kiyosue K, Hazama S, et al. Brain-derived neurotrophic factor regulates cholesterol metabolism for synapse development. J Neurosci 2007; 27: 6417-27.

[41] Delint-Ramirez I, Salcedo-Tello P, Bermudez-Rattoni F. Spatial memory formation induces recruitment of NMDA receptor and PSD-95 to synaptic lipid rafts. J Neurochem 2008; 106: 1658-68.

[42] Francesconi A, Kumari R, Zukin RS. Regulation of group I metabotropic glutamate receptor trafficking and signaling by the caveolar/lipid raft pathway. J Neurosci 2009; 29: 3590-602.

[43] Hou Q, Huang Y, Amato S, et al. Regulation of AMPA receptor localization in lipid rafts. Mol Cell Neurosci 2008; 38: 213-23.

[44] Swanwick CC, Shapiro ME, Yi Z, et al. NMDA receptors interact with flotillin-1 and -2 , lipid raft-associated proteins. FEBS Lett 2009; 583: 1226-30

[45] Besshoh S, Bawa D, Teves L, et al. Increased phosphorylation and redistribution of NMDA receptors between synaptic lipid rafts and post-synaptic densities following transient global ischemia in the rat brain. J Neurochem 2005; 93: 186-94.

[46] Fortin DL, Troyer MD, Nakamura K, et al. Lipid rafts mediate the synaptic localization of alpha-synuclein. J Neurosci 2004; 24: 6715-23.

[47] Naslavsky N, Stein R, Yanai A, et al. Characterization of detergent-insoluble complexes containing the cellular prion protein and its scrapie isoform. J Biol Chem 1997; 272: 6324-31.

[48] Stefani M, Liguri G. Cholesterol in Alzheimer's disease: unresolved questions. Curr Alzheimer Res 2009; 6: 15-29.

[49] Martin V, Fabelo N, Santpere G, et al. Lipid Alterations in Lipid Rafts from Alzheimer's Disease Human Brain Cortex. J Alzheimers Dis 2010; 19(2): 489-502.

[50] Hur JY, Welander H, Behbahani $\mathrm{H}$, et al. Active gamma-secretase is localized to detergent-resistant membranes in human brain. FEBS J 2008; 275: 1174-87.

[51] Cordy JM, Hussain I, Dingwall C, et al. Exclusively targeting betasecretase to lipid rafts by GPI-anchor addition up-regulates betasite processing of the amyloid precursor protein. Proc Natl Acad Sci USA 2003; 100: 11735-40.

[52] Ehehalt R, Keller P, Haass C, et al. Amyloidogenic processing of the Alzheimer beta-amyloid precursor protein depends on lipid rafts. J Cell Biol 2003; 160: 113-23.

[53] Kakio A, Nishimoto SS, Yanagisawa K, et al. Cholesteroldependent formation of GM1 ganglioside-bound amyloid betaprotein, an endogenous seed for Alzheimer amyloid. J Biol Chem 2001; 276: 24985-90.

[54] Tun H, Marlow L, Pinnix I, et al. Lipid rafts play an important role in A beta biogenesis by regulating the beta-secretase pathway. J Mol Neurosci 2002; 19: 31-5.

[55] Eckert GP, Mueller WE. Presenilin 1 modifies neuronal membranes in vivo. Biochem Biophys Res Commun 2009; 382: 673-7.
[56] Schneider A, Schulz-Schaeffer W, Hartmann T, et al. Cholesterol depletion reduces aggregation of amyloid-beta peptide in hippocampal neurons. Neurobiol Dis 2006; 23: 573-7.

[57] Yanagisawa K, Odaka A, Suzuki N, et al. GM1 ganglioside-bound amyloid beta-protein: a possible form of preamyloid in Alzheimer's disease. Nat Med 1995; 1: 1062-6.

[58] Peters I, Igbavboa U, Schutt T, et al. The interaction of betaamyloid protein with cellular membranes stimulates its own production. Biochim Biophys Acta 2009; 1788: 964-72.

[59] Girardot N, Allinquant B, Langui D, et al. Accumulation of flotillin-1 in tangle-bearing neurones of Alzheimer's disease. Neuropathol Appl Neurobiol 2003; 29: 451-61.

[60] Kokubo H, Lemere CA, Yamaguchi H. Localization of flotillins in human brain and their accumulation with the progression of Alzheimer's disease pathology. Neurosci Lett 2000; 290: 93-6.

[61] Igbavboa U, Eckert GP, Malo TM, et al. Murine synaptosomal lipid raft protein and lipid composition are altered by expression of human apoE 3 and 4 and by increasing age. J Neurol Sci 2005; 229-230: 225-32.

[62] Bickel PE, Scherer PE, Schnitzer JE, et al. Flotillin and epidermal surface antigen define a new family of caveolae-associated integral membrane proteins. J Biol Chem 1997; 272: 13793-802.

[63] Schulte T, Paschke KA, Laessing U, et al. Reggie-1 and reggie-2, two cell surface proteins expressed by retinal ganglion cells during axon regeneration. Development 1997; 124: 577-87.

[64] Rao AM, Igbavboa U, Semotuk M, et al. Kinetics and size of cholesterol lateral domains in synaptosomal membranes: modification by sphingomyelinase and effects on membrane enzyme activity. Neurochem Int 1993; 23: 45-52.

[65] van der Luit AH, Budde M, Ruurs P, et al. Alkyl-lysophospholipid accumulates in lipid rafts and induces apoptosis via raft-dependent endocytosis and inhibition of phosphatidylcholine synthesis. J Biol Chem 2002; 277: 39541-7.

[66] Gimpl G, Burger K, Fahrenholz F. Cholesterol as modulator of receptor function. Biochemistry 1997; 36: 10959-74.

[67] Schroeder F, Frolov AA, Murphy EJ, et al. Recent advances in membrane cholesterol domain dynamics and intracellular cholesterol trafficking. Proc Soc Exp Biol Med 1996; 213: 150-77.

[68] Koudinov AR, Koudinova NV. Essential role for cholesterol in synaptic plasticity and neuronal degeneration. FASEB J 2001; 15: 1858-60.

[69] Thiele C, Hannah MJ, Fahrenholz F, et al. Cholesterol binds to synaptophysin and is required for biogenesis of synaptic vesicles. Nat Cell Biol 2000; 2: 42-9.

[70] Schmitz G, Orso E. Intracellular cholesterol and phospholipid trafficking: comparable mechanisms in macrophages and neuronal cells. Neurochem Res 2001; 26: 1045-68.

[71] Igbavboa U, Avdulov NA, Chochina SV, et al. Transbilayer distribution of cholesterol is modified in brain synaptic plasma membranes of knockout mice deficient in the low-density lipoprotein receptor, apolipoprotein E, or both proteins. J Neurochem 1997; 69: 1661-67.

[72] Kirsch C, Eckert GP, Mueller WE. Statins affect cholesterol microdomains in brain plasma membranes. Biochem Pharmacol 2003; 65 843-56.

[73] Igbavboa U, Avdulov NA, Schroeder F, et al. Increasing Age Alters Transbilayer Fluidity and Cholesterol Asymetry in Synaptic Plasma Membrane of Mice. J Neurochem 1996; 66: 1717-25.

[74] Brown DA, London E. Structure and origin of ordered lipid domains in biological membranes. J Membr Biol 1998; 164: 10314.

[75] Simons K, Ikonen E. How cells handle cholesterol. Science 2000; 290: 1721-6.

[76] Schroeder F, Gallegos AM, Atshaves BP, et al. Recent advances in membrane microdomains: rafts, caveolae, and intracellular cholesterol trafficking. Exp Biol Med 2001; 226: 873-90.

[77] Schroeder F, Atshaves BP, McIntosh AL, et al. Sterol carrier protein-2: new roles in regulating lipid rafts and signaling. Biochim Biophys Acta 2007; 1771: 700-18.

[78] Gimpl G, Gehrig-Burger K. Cholesterol reporter molecules. Biosci Rep 2007; 27: 335-58. 
[79] Kabouridis PS, Janzen J, Magee AL, et al. Cholesterol depletion disrupts lipid rafts and modulates the activity of multiple signaling pathways in T lymphocytes. Eur J Immunol 2000; 30: 954-63.

[80] Zidovetzki R, Levitan I. Use of cyclodextrins to manipulate plasma membrane cholesterol content: evidence, misconceptions and control strategies. Biochim Biophys Acta 2007; 1768: 1311-24.

[81] Dalskov SM, Immerdal L, Niels-Christiansen LL, et al. Lipid raft localization of GABA A receptor and $\mathrm{Na}+, \mathrm{K}+$-ATPase in discrete microdomain clusters in rat cerebellar granule cells. Neurochem Int 2005; 46: 489-99.

[82] Oldfield S, Hancock J, Mason A, et al. Receptor-mediated suppression of potassium currents requires colocalization within lipid rafts. Mol Pharmacol 2009; 76: 1279-89.

[83] Huang P, Xu W, Yoon SI, et al. Cholesterol reduction by methylbeta-cyclodextrin attenuates the delta opioid receptor-mediated signaling in neuronal cells but enhances it in non-neuronal cells. Biochem Pharmacol 2007; 73: 534-49.

[84] Avdulov NA, Chochina SV, Igbavboa U, et al. Amyloid betapeptides increase annular and bulk fluidity and induce lipid peroxidation in brain synaptic plasma membranes. J Neurochem 1997; 68: 2086-91.

[85] Bodovitz S, Klein WL. Cholesterol modulates alpha-secretase cleavage of amyloid precursor protein. J Biol Chem 1996; 271 : 4436-40.

[86] Fassbender K, Simons M, Bergmann C, et al. Simvastatin strongly reduces levels of Alzheimer's disease beta -amyloid peptides Abeta 42 and Abeta 40 in vitro and in vivo. Proc Natl Acad Sci USA 2001; 98: 5856-61.

[87] Frears ER, Stephens DJ, Walters CE, et al. The role of cholesterol in the biosynthesis of beta-amyloid. Neuroreport 1999; 10: 16991705 .

[88] Kojro E, Gimpl G, Lammich S, et al. Low cholesterol stimulates the nonamyloidogenic pathway by its effect on the alpha -secretase ADAM 10. Proc Natl Acad Sci USA 2001; 98: 5815-20.

[89] Kirsch C, Eckert GP, Mueller WE. Cholesterol attenuates the membrane perturbing properties of beta-amyloid peptides. Amyloid 2002; 9: 149-59.

[90] Dos Santos SM, Weber CC, Franke C, et al. Cholesterol: Coupling between membrane microenvironment and $\mathrm{ABC}$ transporter activity. Biochem Biophys Res Commun 2007; 354: 216-21.

[91] Simons K, Ikonen E. Functional rafts in cell membranes. Nature 1997; 387: 569-72.

[92] Hamelin BA, Turgeon J. Hydrophilicity/lipophilicity: relevance for the pharmacology and clinical effects of $\mathrm{HMG}-\mathrm{CoA}$ reductase inhibitors. Trends Pharmacol Sci 1998; 19: 26-37.

[93] Lousberg TR, Denham AM, Rasmussen JR. A comparison of clinical outcome studies among cholesterol-lowering agents. Ann Pharmacother 2001; 35: 1599-07.

[94] Corsini A, Bellosta S, Baetta R, et al. New insights into the pharmacodynamic and pharmacokinetic properties of statins. Pharmacol Ther 1999; 84: 413-28.

[95] Eckert GP, Hooff GP, Strandjord D, et al. Regulation of the brain isoprenoids farnesyl- and geranylgeranyl pyrophosphate is altered in Alzheimer disease. Neurobiol Dis 2009; 35: 251-7.

[96] Schachter M. Chemical, pharmacokinetic and pharmacodynamic properties of statins: an update. Fundam Clin Pharmacol 2005; 19: 117-25.

[97] Johnson-Anuna LN, Eckert GP, Keller JH, et al. Chronic administration of statins alters multiple gene expression patterns in mouse cerebral cortex. J Pharmacol Exp Ther 2005; 312: 786-93.

[98] Eckert GP, Kirsch C, Mueller WE. Differential effects of lovastatin treatment on brain cholesterol levels in normal and apoE-deficient mice. Neuroreport 2001; 12: 883-7.

[99] Burns MP, Igbavboa U, Wang L, et al. Cholesterol distribution, not total levels, correlate with altered amyloid precursor protein processing in statin-treated mice. Neuromolecular Med 2006; 8: 319-28.

[100] Franke C, Nöldner M, Abdel-Kader R, et al. Bcl-2 upregulation and neuroprotection in guinea pig brain following chronic simvastatin treatment. Neurobiol Dis 2007; 25: 438-45.
[101] Zacco A, Togo J, Spence K, et al. 3-hydroxy-3-methylglutaryl coenzyme A reductase inhibitors protect cortical neurons from excitotoxicity. J Neurosci 2003; 23: 11104-11.

[102] Ponce J, de la Ossa NP, Hurtado O, et al. Simvastatin reduces the association of NMDA receptors to lipid rafts: a cholesterolmediated effect in neuroprotection. Stroke 2008; 39: 1269-75.

[103] Petro KA, Dyer MA, Yowler BC, et al. Disruption of lipid rafts enhances activity of botulinum neurotoxin serotype A. Toxicon 2006; 48: 1035-45.

[104] Petro KA, Schengrund CL. Membrane raft disruption promotes axonogenesis in n2a neuroblastoma cells. Neurochem Res 2009; 34: 29-37.

[105] Guirland C, Suzuki S, Kojima M, et al. Lipid rafts mediate chemotropic guidance of nerve growth cones. Neuron 2004; 42: 51 62 .

[106] Castanho MA, Coutinho A, Prieto MJ. Absorption and fluorescence spectra of polyene antibiotics in the presence of cholesterol. J Biol Chem 1992; 267: 204-9.

[107] Shahidi F, Miraliakbari H. Omega-3 fatty acids in health and disease: part 2-health effects of omega-3 fatty acids in autoimmune diseases, mental health, and gene expression. J Med Food 2005; 8: 133-48.

[108] Innis SM. Dietary omega 3 fatty acids and the developing brain Brain Res 2008; 1237: 35-43.

[109] Bourre JM. Roles of unsaturated fatty acids (especially omega-3 fatty acids) in the brain at various ages and during ageing. J Nutr Health Aging 2004; 8: 163-74.

[110] Fan YY, Ly LH, Barhoumi R, et al. Dietary docosahexaenoic acid suppresses $\mathrm{T}$ cell protein kinase $\mathrm{C}$ theta lipid raft recruitment and IL-2 production. J Immunol 2004; 173: 6151-60.

[111] Ma DW, Seo J, Switzer KC, et al. n-3 PUFA and membrane microdomains: a new frontier in bioactive lipid research. $\mathrm{J}$ Nutr Biochem 2004; 15: 700-6.

[112] Ma DW, Seo J, Davidson LA, et al. n-3 PUFA alter caveolae lipid composition and resident protein localization in mouse colon. FASEB J 2004; 18: 1040-2.

[113] Stulnig TM, Huber J, Leitinger N, et al. Polyunsaturated eicosapentaenoic acid displaces proteins from membrane rafts by altering raft lipid composition. J Biol Chem 2001; 276: 37335-40.

[114] Stulnig TM, Berger M, Sigmund T, et al. Polyunsaturated fatty acids inhibit $\mathrm{T}$ cell signal transduction by modification of detergent-insoluble membrane domains. J Cell Biol 1998; 143: 637-44.

[115] Fan YY, McMurray DN, Ly LH, et al. Dietary (n-3) polyunsaturated fatty acids remodel mouse T-cell lipid rafts. J Nutr 2003; 133: 1913-20.

[116] Switzer KC, Fan YY, Wang N, et al. Dietary n-3 polyunsaturated fatty acids promote activation-induced cell death in Th1-polarized murine CD4+ T-cells. J Lipid Res 2004; 45: 1482-92.

[117] Chapkin RS, Wang N, Fan YY, et al. Docosahexaenoic acid alters the size and distribution of cell surface microdomains. Biochim Biophys Acta 2008; 1778: 466-71.

[118] Suzuki H, Park SJ, Tamura M, et al. Effect of the long-term feeding of dietary lipids on the learning ability, fatty acid composition of brain stem phospholipids and synaptic membrane fluidity in adult mice: a comparison of sardine oil diet with palm oil diet. Mech Ageing Dev 1998; 101: 119-28.

[119] Green KN, Martinez-Coria H, Khashwji $\mathrm{H}$, et al. Dietary docosahexaenoic acid and docosapentaenoic acid ameliorate amyloid-beta and tau pathology via a mechanism involving presenilin 1 levels. J Neurosci 2007; 27: 4385-95

[120] Lim GP, Calon F, Morihara T, et al. A diet enriched with the omega-3 fatty acid docosahexaenoic acid reduces amyloid burden in an aged Alzheimer mouse model. J Neurosci 2005; 25: 3032-40.

[121] Lukiw WJ, Bazan NG. Docosahexaenoic acid and the aging brain. J Nutr 2008; 138: 2510-4.

[122] Oksman M, Iivonen H, Hogyes E, et al. Impact of different saturated fatty acid, polyunsaturated fatty acid and cholesterol containing diets on beta-amyloid accumulation in APP/PS1 transgenic mice. Neurobiol Dis 2006; 23: 563-72. 
[123] Sahlin C, Pettersson FE, Nilsson LN, et al. Docosahexaenoic acid stimulates non-amyloidogenic APP processing resulting in reduced Abeta levels in cellular models of Alzheimer's disease. Eur J Neurosci 2007; 26: 882-89.

[124] Yavin E. Docosahexaenoic acid: a pluripotent molecule acting as a membrane fluidizer, a cellular antioxidant and a modulator of gene expression. Nutr Health 2006; 18: 261-2.

[125] Chapkin RS, McMurray DN, Davidson LA, et al. Bioactive dietary long-chain fatty acids: emerging mechanisms of action. Br J Nutr 2008; 100: 1152-7.
[126] Stillwell W, Wassall SR. Docosahexaenoic acid: membrane properties of a unique fatty acid. Chem Phys Lipids 2003; 126: 127.

[127] Stillwell W, Shaikh SR, Zerouga M, et al. Docosahexaenoic acid affects cell signaling by altering lipid rafts. Reprod Nutr Dev 2005; 45: 559-79.

[128] Yaqoob P. The nutritional significance of lipid rafts. Annu Rev Nutr 2009; 29: 257-82.

[129] Hering H, Lin CC, Sheng M. Lipid rafts in the maintenance of synapses, dendritic spines, and surface AMPA receptor stability. J Neurosci 2003; 23: 3262-71.

(C) Gunter P. Eckert; Licensee Bentham Open.

This is an open access article licensed under the terms of the Creative Commons Attribution Non-Commercial License (http://creativecommons.org/licenses/by$\mathrm{nc} / 3.0 /$ ), which permits unrestricted, non-commercial use, distribution and reproduction in any medium, provided the work is properly cited. 